\title{
Design and Simulation of a Boost-Microinverter for Optimized Photovoltaic System Performance
}

\author{
Shahd Fadhil Jaber**, Amina Mahmoud Shakir** \\ *Electronic and Communications Engineering Department, College of Engineering, Al-Nahrain University, Iraq \\ **Electronic and Communications Engineering Department, College of Engineering, Al-Nahrain University, Iraq \\ (st.shahd.fadhil.1@ced.nahrainuniv.edu.iq, aminaalkafajiam@gmail.com) \\ † Corresponding Author; Shahd Fadhil, st.shahd.fadhil.1@ced.nahrainuniv.edu.iq ; Tel: 009647901243740 ,
}

Received: 06.05.2021 Accepted:14.06.2021

\begin{abstract}
Renewable energy sources are the most important type of energy since they are clean and do not affect the environment. Solar energy is a kind of renewable energy that is more popular than other sources. Photovoltaic (PV) systems use solar energy as a source of electricity. The main parts of any PV system are a PV panel, DC-DC converter with maximum power point tracking, and a DC-AC inverter with adequate control. The Photovoltaic system for this study comprises a boost converter, a full-bridge inverter, and an LCL filter. The boost converter is controlled using the Maximum power point Tracking (MPPT) algorithm, while the inverter is controlled through a Sinusoidal Pulse Width Modulator (SPWM) achieved in an open loop. This paper provides a comparison performance between perturbation and observation [P\&O] and particle swarm optimization [PSO] algorithms to get MPP for the PV system. When the irradiance changes, the micro-inverter adapts under partial conditions. The micro-inverter is designed by MATLAB / Simulink/2020a software. The input maximum voltage from the PV is $80 \mathrm{~V}$ direct current (DC) while the alternating current $[\mathrm{Ac}]$ output voltage is $110 \mathrm{Vrms}$. The output voltage and current total harmonic distortion (THD) ratios are $2.58 \%$ and $2.76 \%$ respectively when the P\&O algorithm is used, while that when using the PSO algorithm are $2.45 \%$ and $2.58 \%$. The PV system efficiency achieved by using P\&O, PSO are $95.7 \%, 96.8 \%$.
\end{abstract}

Keywords- photovoltaic; MPPT algorithm; boost converter; H- Bridge inverter

\section{1- Introduction}

The need for electricity has become very necessary than before the increase in population and the development of industries in the world. Electric power is generated at most by using the fossil fuels such as oil, natural gas, coal, etc. Fossil fuels are considered sources of environmental pollution; research began on renewable energy such as wind energy, thermal energy, hydropower, solar energy, etc., as renewable energy is considered a clean and environmentally friendly source. Photovoltaic energy is the most common renewable energy source. A Photovoltaic (PV) panel is used to produce electrical energy from solar energy when sunlight falls on the PV panel. PV systems are either on-grid or off-grid (standalone). Figure. 1 shows an on-grid PV system which mainly consists of a PV array (series-parallel combination of PV panels ), inverter, and suitable control circuits, while there must be a method for storing energy for off-grid PV system during periods of unavailability of solar energy[1].

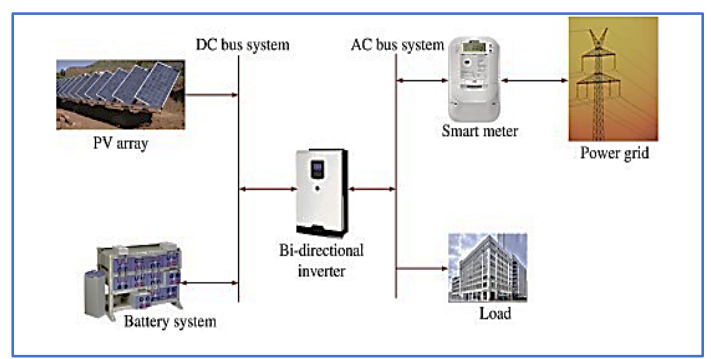

Figure1. Grid-connected PV system

PV arrays often operate under incompatible conditions due to partial shading and varying orientations of the panels. This will reduce the PVarray power production. Micro-inverter is one of the suitable solutions to limit this drawback.

Numerous studies have been carried out on the microinverter design and performance for PV systems. A grid-connected boost half- bridge photovoltaic micro-inverter with pulse width modulated (PWM) control is proposed in[2]. The study uses fuzzy logic control (FLC) to control the MPPT for the photovoltaic system as compared with the classical $\mathrm{P} \& \mathrm{O}$ and IC methods. A DC-AC converter that connects the DC to DC converter flowed by the inverter with a single-stage topology. A study in[3] presents an on-grid PV system that has a better power quality. The system consists of the PV panel, boost 
converter with PI controller, and Fuzzy Controller, inverter topology. The shunt active power filter (SAF) is designed to lower the harmonics. The study in [4] presents the design of a high power grid integrated solar energy system (GISES). The performance of two-stage GISES with isolated multi-output DC-DC converters and DC-AC multilevel inverters. A cascaded H-bridge multilevel inverter (CHBMI) with isolated multiple-output zeta converter is used. The maximum power point tracking (MPPT) method, based on the firefly algorithm, is implemented on the isolated multiple output zeta converter to ensure maximum power extraction at adverse irradiation conditions. The power quality improvement and active power exchange through a band stop generalized integral control, and the grid synchronization is achieved through an enhanced phase-locked loop method. The study in[5] was carried out by the hybrid Artificial Neural Network (ANN) - Newton Raphson (NR). It is introduced to reduce the undesirable lower-order harmonic content in the Full-Bridge multilevel inverter for the photovoltaic panel. Harmonics are removed by the excellent choice of switching angles by exploiting the Selective Harmonic Elimination pulse width modulation (SHEPWM) technique accompanying a unified algorithm to optimize and lessen the THD. The CHB-MLI is combined with a conventional boost converter, it boosts converters the PV panel voltage to a higher DC-link voltage. The Maximum Power Point (MPP) based Perturb and Observe (P\&O) algorithm is used for stable performance and effective operation of the PV panel. The proposed system is tested on an 11-level H-bridge inverter, the work is carried out in MATLAB/Simulink software.

The present research focuses on the micro-inverter that consists of a boost converter, a comparison performance between Perturbation and observation (P\&O), and Particle Swarm Optimization (PSO) for harvesting the MPPT algorithm, and a full-bridge inverter with adequate control.

\section{2- PV System Inverter Configurations}

The photovoltaic system inverter configuration can be categorized into three essential types: center-inverter, stringinverter, and micro-inverter. Figure (2.a) shows the central inverter in which it is connected to a series-parallel combination of solar cells and uses the MPPT algorithm for optimum operation, as the climatic conditions such as temperature, radiation, etc. affect the efficiency and performance of the photovoltaic system. Partial shading is one of the significant problems that occur for several reasons and hence reduces the efficiency and performance of the system. A string inverter is connected to each series PV group as shown in Figure (2.b) to reduce the partial shading effect. MPPT algorithm control is used for each chain, but this is not sufficient to solve the partial shading problem. A new type of inverter that overcomes partial shading is called the microinverter in which each solar panel has its own microinverter as shown in Figure (2.c). In this configuration, every microinverter uses a separate MPPT algorithm as a result the partial shading effect is eliminated. In this case, any malfunction of the inverter does not affect the other. The microinverter is more efficient than the central and string inverter but it is the most expensive of them[6][7].

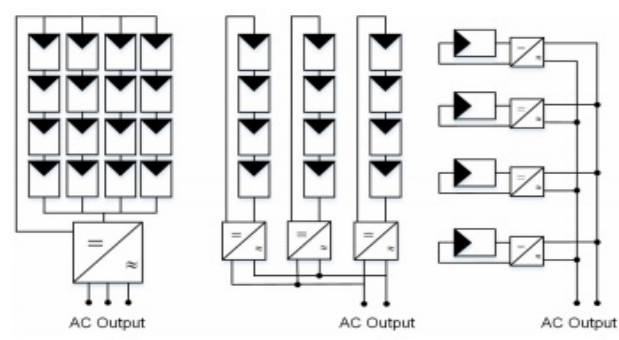

Figure2. Structures of the solar photovoltaic inverter (a) Central-inverter (b) String- inverter (c) Micro-inverter

\section{System Description}

The micro-inverter consists of two stages: the first stage is a DC-DC converter and the second stage is a DC-AC inverter, controllers, and output filter as shown in figure 3 . The input voltage and current to the DC boost converter is from the solar panel The the voltage and current is converted from DC to $\mathrm{AC}$ by full-bridge inverter. To operate the PV panel at its maximum power point a suitable method of tracking is used. An LCL filter is designed and connected at the inverter output to reduce the voltage and current harmonics which will be injected into the grid. The following sections will describe the main parts of the suggested system.

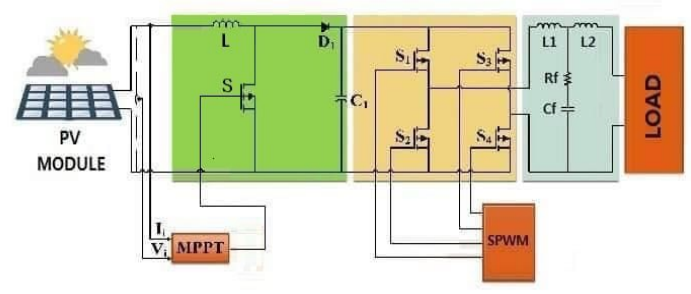

Figure3. PV system scheme

\section{a- PV panel and MPPT}

The PV cell output characteristic is non-linear, which is affected by light and temperature. Based on these output features, the MPPT method must be used. The most common tracking methods are Constant voltage (CV), Hill Climbing (HC), Fuzzy Logic Control (FLC), Perturb and Observe (P\&O), Artificial bee colony (ABC), Incremental conductance (IC), and Particle Swarm Optimization (PSO). Each algorithm has its own characteristics to obtain the maximum power[8].

\section{- Perturbation and Observation (P\&O)}

The P\&O method is the most common method for the MPPT due to its simple structure and a few numbers of needful measured parameters. The conception behind the P\&O algorithm depends on observation of the PV panel output power and its perturbation through the variation of the voltage or the current of PV panel operation. The algorithm increases or decreases continuously the reference current or voltage 
based on the past value of energy until arrives the MPP. Figure 4 illustrate the flowchart of the P\&O MPPT algorithm[9][10].

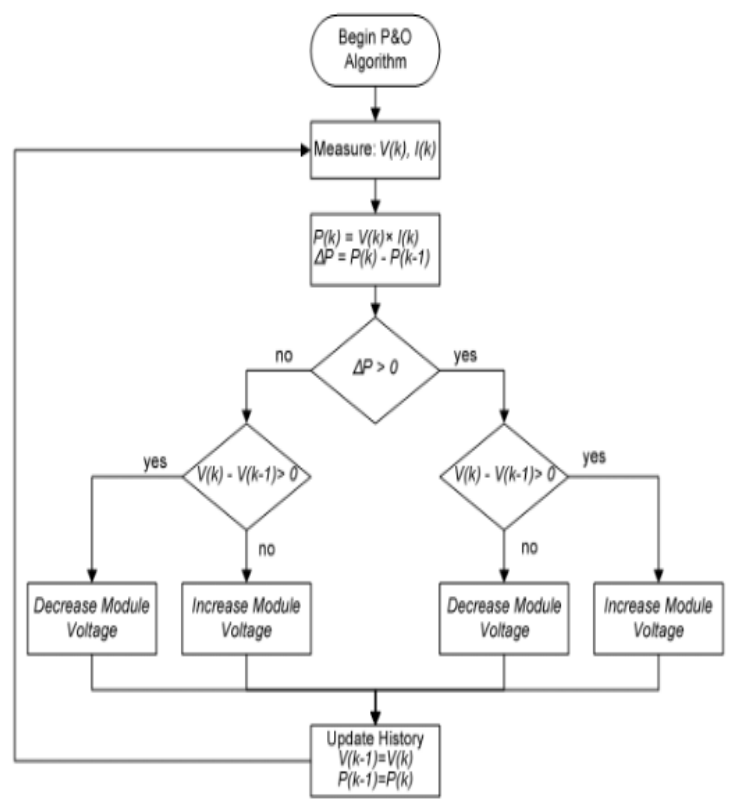

Figure4. Flowchart of Perturbation and Observation MPPT algorithm

\section{- $\quad$ Particle Swarm Optimization (PSO)}

This technique uses a PSO algorithm which is based on fish or bird behavior. PSO algorithm is used to set the possible maximizing or minimizing point. It begins with a group of random particles and continues to update the particles until reaching the best possible solution. Each particle has two values: the first is the best local value, while the second is the global value. The first value is for every individual, the second value is for every population Figure 5. Illustrate the main block diagram for the PSO algorithm. The following equations $(1,2)$ are used to organize the PSO algorithm:

$v(i+1)=w i v i(t)+c 1 r 1($ Pbest,$i-x i(t))+$

c2 $r 2$ (Gbest, $i-x i(t))$

$$
x(i+1)=x i(t)+v(i+1)
$$

Where

$X i(t)$ : particle swarm on the curve, wi: is the inertia weight, $V i$ : the velocity of the particle on the curve, $V i(t+$ $1)$ : the updated velocity of the particle on the curve, $X i(t+1)$ : the updated position of the particles,cl: acceleration factor for vector $(P i(t)-X i(t)), \mathrm{c} 2$ : acceleration factor for vector $(g \mathrm{i}(t)$ $-X i(t)),[\mathrm{r} 1, \mathrm{r} 2]$ : the random values in between[0,1], Pbest : is the personal best solution or best private solution of particle,Gbest : is the global best and i: is the swarm number[11][12]. Figure 5 shows the flow chart for the PSOMPPT algorithm.

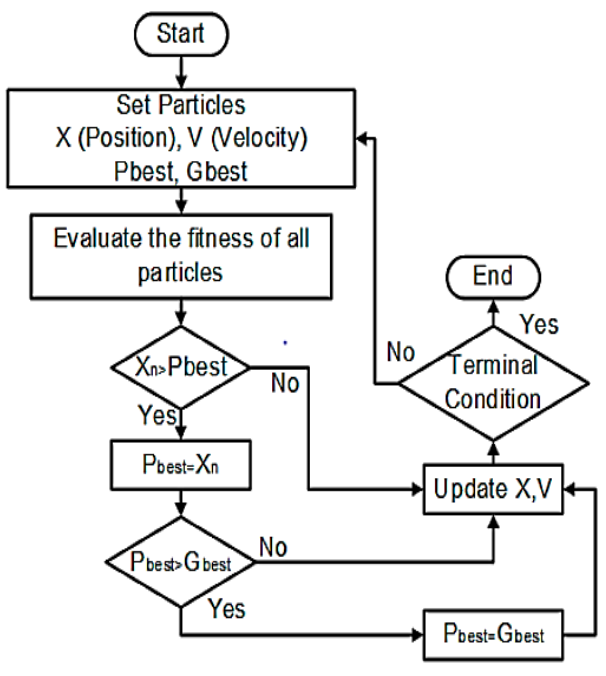

Figure5. Flowchart of particle swarm optimization MPPT algorithm

\section{b- Boost-Converter}

The boost-converter is a type of non- isolation transformer, also known as the step-up converter. It comprises an inductor (L), a diode (D), a switch (S), and an output capacitor (Cout). The boost converter operates in two modes by turning the switch on and off as follow[13]:

- switch-on

When the switch is stated on, the current flowing from the supply to the inductor (L) and hence stores energy in its magnetic field. In this case, the diode is reverse biased and the initial stored energy in the output capacitor will feed the load as shown in figure (6.a)

- $\quad$ switch-off

When the switch is off, the inductor current will decay and the diode will be forward biased. The capacitor will be charged and the voltage across the load will increase as shown in figure (6.b)

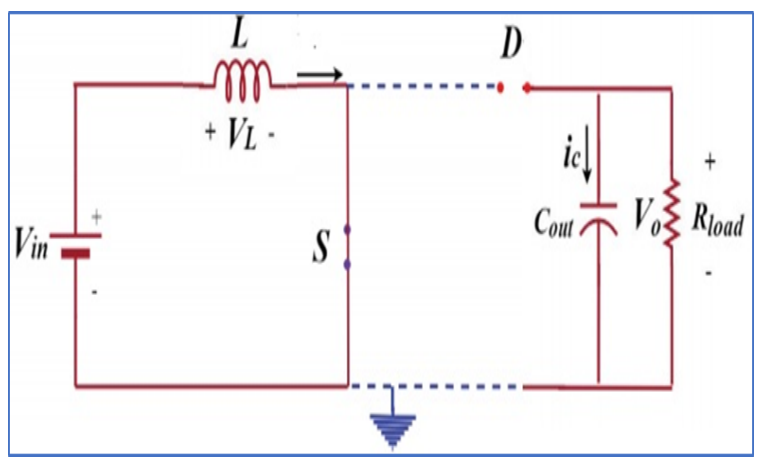

(a) Switch on-mode 


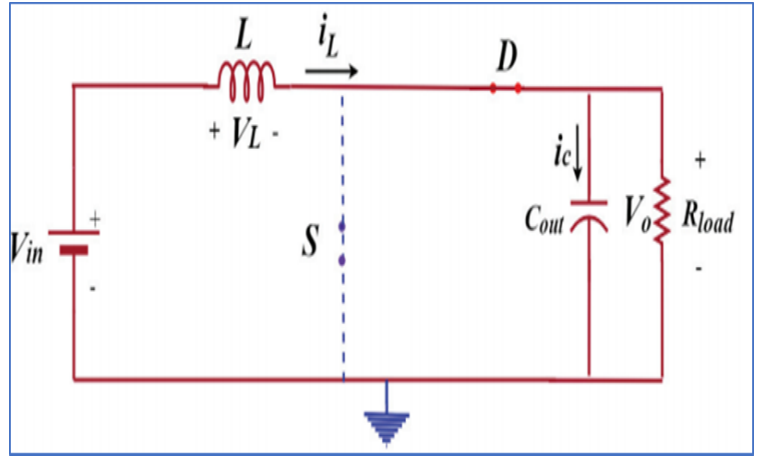

(a) Switch off-mode

Figure6. Operation modes of the boost converter

The relationship between the boost converter input voltage (Vin) and output voltage (Vo) is given the by duty cycle (D) ;

$$
\frac{\mathrm{v}_{0}}{\mathrm{v}_{\mathrm{i}}}=\frac{1}{1-\mathrm{D}}
$$

The inductance $(\mathrm{L})$ of the boost-converter is can be calculated as:

$$
\mathrm{L}=\frac{\mathrm{Vi}(\mathrm{Vo}-\mathrm{Vi})}{\mathrm{Fsw} \times \Delta \mathrm{I} \times \mathrm{Vo}_{0}}
$$

Where $\left(\mathrm{F}_{\mathrm{sw}}\right)$ is the switching frequency of the boostconverter, $(\Delta I)$ is the maximum ripple value of output current. The output capacitor is used to reduce the output voltage ripple and can be given by the following equation(5):

$$
\mathrm{C} \geq \frac{\mathrm{Io}(\mathrm{Vo}-\mathrm{Vi})}{\mathrm{Fsw} \times \Delta \mathrm{V} \times \mathrm{Vo}}
$$

As such, it is guaranteed that the output voltage of the boost converter is higher than the voltage of the photovoltaic panel[14].

\section{c- full-Bridge Inverter (H- Bridge)}

The main purpose of the inverter is the conversion of the direct current input voltage to the alternating current output voltage. The inverter consists of four switches as shown in figure 7 .

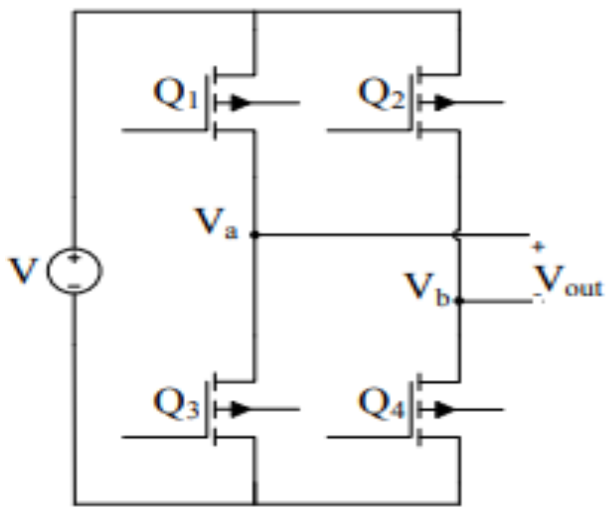

Figure7. Circuit of Full-bridge inverter5

The switches are controlled using pulse width modulation (PWM). There is more than one type of PWM. Sinusoidal Pulse Width Modulation (SPWM) technology is the most widely used as it is efficient in reducing harmonic levels. There are two types of SPWM connectivity: the first type is bipolar and the second type Unipolar. Unipolar is used due to its lower harmonics as compared with bipolar. The SPWM technology depends on a comparison between a sinusoidal reference wave and a triangular carrier wave. The sinusoidal reference wave is used to set switch operation. The triangular carrier wave frequency determined switching frequency. The frequency of the reference waveform is important because it determines the frequency of the inverter [15].The inverter output frequency is depending on the sinusoidal reference frequency. The switch operation is shown in table 1.

Table 1. Switching situations of $\mathrm{H}$-bridge

\begin{tabular}{|c|c|c|c|c|}
\hline Situations & $\begin{array}{c}\text { Conducting } \\
\text { switching }\end{array}$ & $\mathrm{Va}$ & $\mathrm{Vb}$ & Vout \\
\hline$(1)$ & $(\mathrm{Q} 1)$ and (Q3) & $(\mathrm{V} / 2)$ & $(-\mathrm{V} / 2)$ & $\mathrm{V}$ \\
\hline$(2)$ & $(\mathrm{Q} 2)$ and (Q4) & $(\mathrm{V} / 2)$ & $(-\mathrm{V} / 2)$ & $-\mathrm{V}$ \\
\hline$(3)$ & $(\mathrm{Q} 1)$ and $(\mathrm{Q} 2)$ & $(\mathrm{V} / 2)$ & $(\mathrm{V} / 2)$ & 0 \\
\hline$(4)$ & $(\mathrm{Q} 3)$ and $(\mathrm{Q} 4)$ & $(-\mathrm{V} / 2)$ & $(-\mathrm{V} / 2)$ & 0 \\
\hline
\end{tabular}

\section{d- LCL Filter}

The circuit of the LCL filter consists of two inductors $\left(L_{f} 1\right.$, $\left.\mathrm{L}_{\mathrm{f} 2}\right)$, a damping resistor $\left(\mathrm{R}_{\mathrm{f}}\right)$, and capacitance $\left(\mathrm{C}_{\mathrm{f}}\right)$ as shown in figure 8. The LCL filter helps SPWM technology to reduce the harmonics produced by the inverter switching that results in a power quality reduction of the system. The THD is the PV system must be low for rising power quality[16][17].

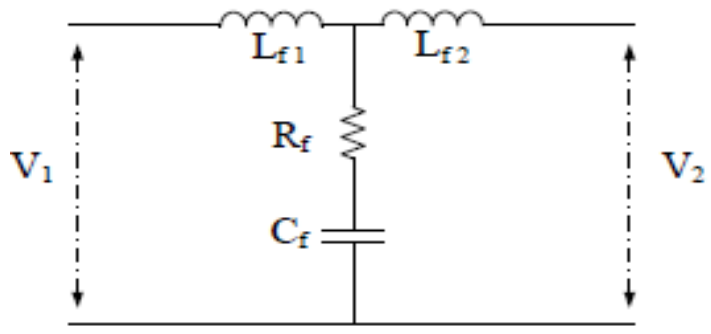

Figure8. The structure of the LCL filter

The resonance frequency $\left(f_{\text {res }}\right)$ can be presented as

$$
f_{\text {res }}=\frac{1}{2 \pi} \sqrt{\frac{L_{f 1}+L_{f 2}}{L_{f 1} \cdot L_{f 2} \cdot c_{f}}}
$$

The range of $f_{\text {res }}$ is defined as

$$
10 f_{g}<f_{\text {res }}<0.5 f_{s}
$$

where (fs) is the switching frequency of the inverter,(fg) is the output frequency from the system

$\mathrm{Zb}$ is base impedance and $\mathrm{Cb}$ is capacitance to calculated as

$$
\begin{aligned}
z_{b} & =\frac{V_{r m s} 2}{p} \\
c_{b} & =\frac{1}{2 \pi f g z b}(9)
\end{aligned}
$$

The filter capacitor $\left(\mathrm{C}_{\mathrm{f}}\right)$ is calculated as

$$
c_{f}<0 \cdot 05 \cdot c_{b}
$$


The damping resistor (Rf) is defined by

$$
R_{f}=\frac{1}{6 \pi f_{\text {res }} C f}
$$

The value first inductor $\left(\mathrm{L}_{\mathrm{f}} 1\right)$ of the inverter side given as

$$
L_{f 1}=\frac{v_{d C}}{16 f_{s} \cdot \Delta \operatorname{Imax}}
$$

The maximum current ripple $(\Delta \operatorname{Imax})$ is calculated as

$$
\Delta \operatorname{Imax}=0.1 \frac{p \cdot \sqrt{2}}{v_{r m s}}
$$

The value second inductor (Lf2) of load side given as

$$
L_{f 2}=0.8 L_{f 1}
$$

\section{Matlab Simulation and Results}

The micro inverter is implemented using the MATLAB Simulink program. It's consists of a solar panel on the left side, followed by a boost converter. The boost converter duty cycle is determined by the maximum power point algorithm. Two different MPPT algorithms the P\&O and the PSO are chosen to examine their ability in tracking the MPP located below the boost converter. It also contains a full-bridge inverter that converts the voltage from DC to AC. The LCL filter is attached to the right side of the inverter and the load, as shown in figure 9.

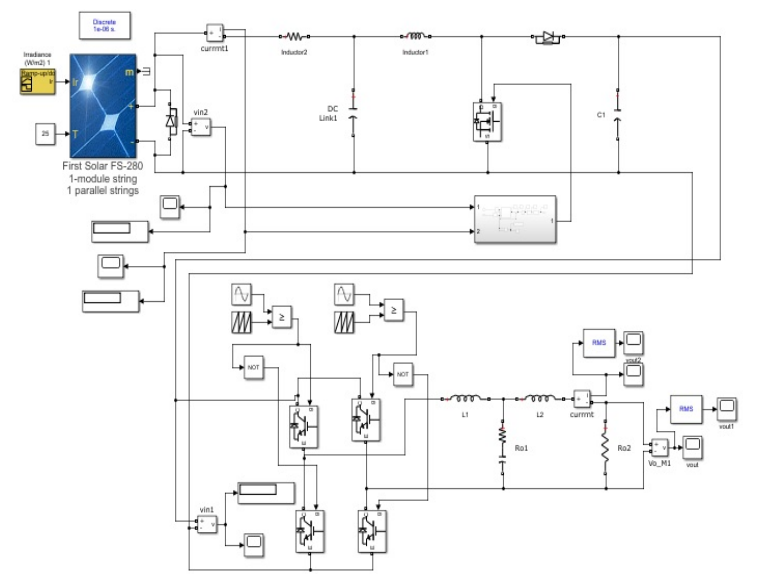

Figure9. The designed micro inverter

The PV panel model used is First Solar FS-280 with the specifications shown in table 2 .

Table 2.the Specifications of PV Panel

\begin{tabular}{|l|c|l|}
\hline Specifications & symbol & Value \\
\hline Power & $\mathrm{P}$ & $79.744 \mathrm{~W}$ \\
\hline Voltage (in open circuit) & VOC & $91.5 \mathrm{~V}$ \\
\hline Max. power voltage & Vmp & $71.2 \mathrm{~V}$ \\
\hline Current (in short circuit) & Isc & $1.22 \mathrm{~A}$ \\
\hline Max. power current & Imp & $1.12 \mathrm{~A}$ \\
\hline
\end{tabular}

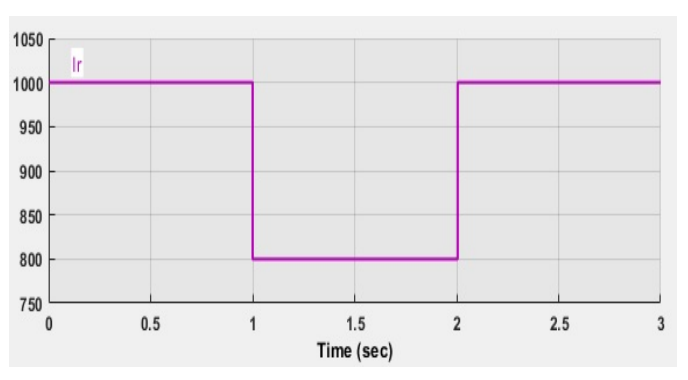

Figure10. The curves of irradiation

The solar irradiation on the PV panel is started from [1000 $\left.\mathrm{w} / \mathrm{m}^{2}\right]$ to $\left[800 \mathrm{w} / \mathrm{m}^{2}\right]$ at time $1 \mathrm{sec}$ and then increases to $1000 \mathrm{w} / \mathrm{m}^{2}$ at time $2 \mathrm{sec}$ as shown in figure 10 . According to irradiation change, the output current and voltage of the PV panel are changed between $(0.96 \mathrm{~A}-1.22 \mathrm{~A})$ and $(59 \mathrm{~V}-81 \mathrm{~V})$ respectively as shown in Figure 11.

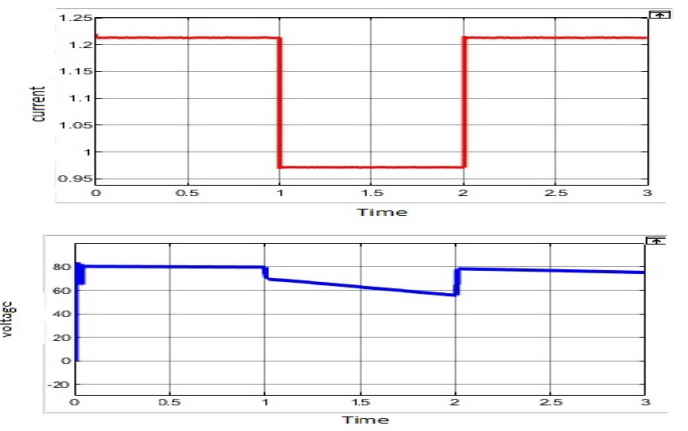

Figure11. The output current and voltage of the PV panel

To convert DC to DC values, the Specifications of the boost converter are set in table 3 .

Table 3. Boost-converter Specifications

\begin{tabular}{|l|l|}
\hline Specifications & Value \\
\hline Inductor, $\mathrm{L}$ & $2.5 \mathrm{mH}$ \\
\hline Input capacitor, $\mathrm{Ci}$ & $10 \mathrm{uF}$ \\
\hline Output capacitor, $\mathrm{Co}$ & $3 \mathrm{uF}$ \\
\hline Switching frequency, $\mathrm{F}_{\mathrm{SW}}$ & $50 \mathrm{KHZ}$ \\
\hline input voltage, $\mathrm{Vi}$ & $81 \mathrm{~V}$ \\
\hline output voltage, Vo & $164 \mathrm{~V}$ \\
\hline
\end{tabular}

During the change of the irradiation values, the duty cycle is determined by using the MPPT algorithm. Compassion between P\&O and PSO to track the MPP is used. The duty cycle of the $\mathrm{P} \& \mathrm{O}$ algorithm is equal to 0.29 , while The PSO algorithm is equal to 0.3 as shown in figure. 12 . 


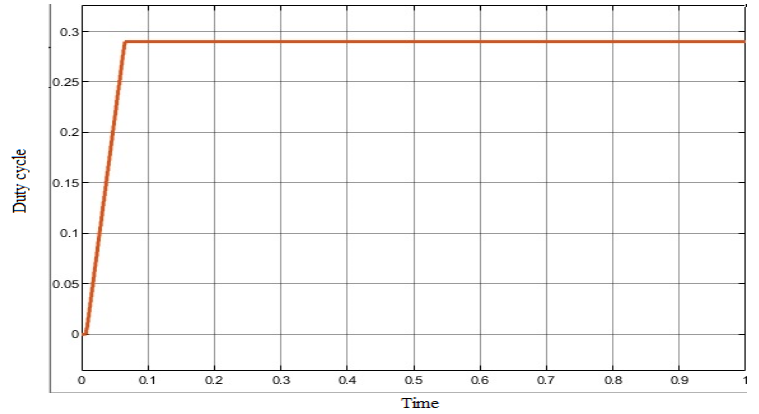

(a) $\mathrm{P} \& \mathrm{O}$

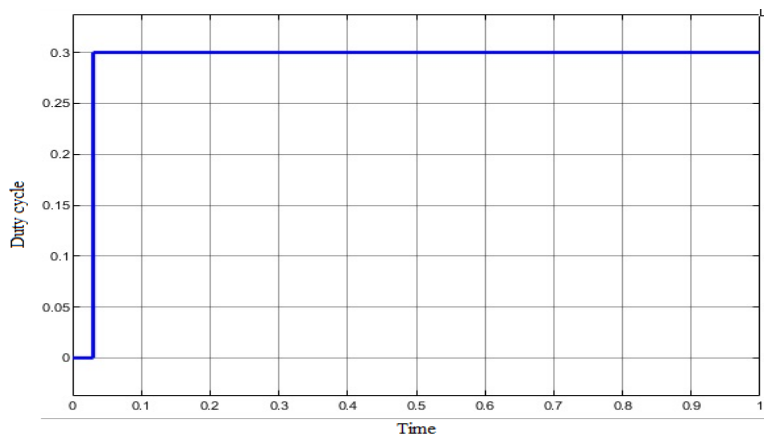

(b) PSO

Figure.12 The duty cycle of the $\mathrm{P} \& \mathrm{O}$ algorithm and PSO algorithm

Both P\&O and PSO algorithms have the capability of tracking the MPP. The P\&O algorithm found the MPP at $0.08 \mathrm{~s}$, while the PSO algorithm tracks the MPP at $0.03 \mathrm{~s}$ as shown in figure 12 . The output voltage of the boost converter is about (158-164 V) as illustrated in Figure 13.

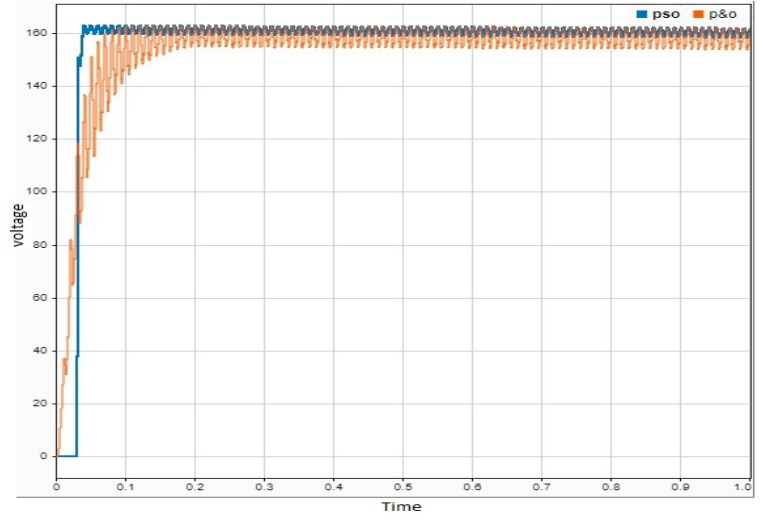

Figure13. .The PSO and the $\mathrm{P} \& \mathrm{O}$ tracking response

In order to convert the $\mathrm{DC}$ values to the $\mathrm{AC}$, a full-bridge inverter is used. The voltage at $110 \mathrm{Vrms}$ and frequency of 60 $\mathrm{Hz}$. The considered values of the LCL filter are given in table 4.
Table 4.the Specifications of the LCL filter

\begin{tabular}{|l|l|}
\hline Specifications & Value \\
\hline Output frequency ,fg & $60 \mathrm{HZ}$ \\
\hline Input inverter voltage, Vdc & $164 \mathrm{~V}$ \\
\hline Output voltage, Vrms & $110 \mathrm{~V}$ \\
\hline Inverter side inductor,L1 & $2 \mathrm{mH}$ \\
\hline load side inductor,L2 & $1.6 \mathrm{mH}$ \\
\hline Filter capacitor, Cf & $3 \mathrm{uF}$ \\
\hline Damping resistor , Rf & $20 \Omega$ \\
\hline
\end{tabular}

The AC output current and voltage in which the maximum values are $0.24 \mathrm{~A}$ and $155 \mathrm{~V}$ respectively. Figure 14 also shows a comparison between the two MPPT algorithms (P\&O and PSO) and their effect on the output current and voltage. The tracking performance of the PSO algorithm is better than the P\&O algorithm.

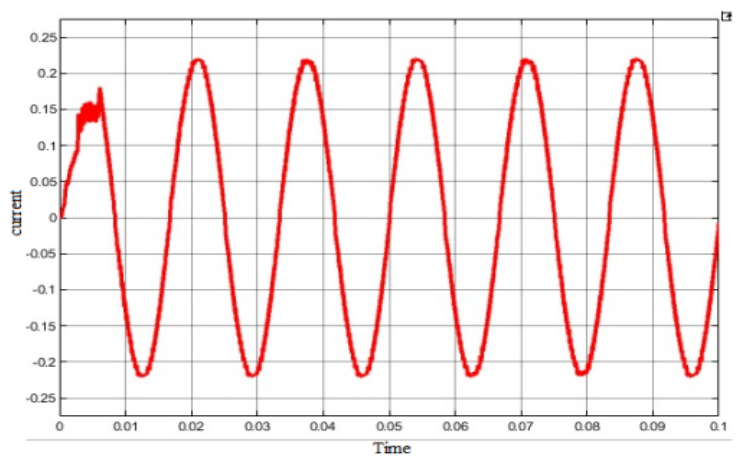

(a) $\mathrm{P} \& \mathrm{O}$

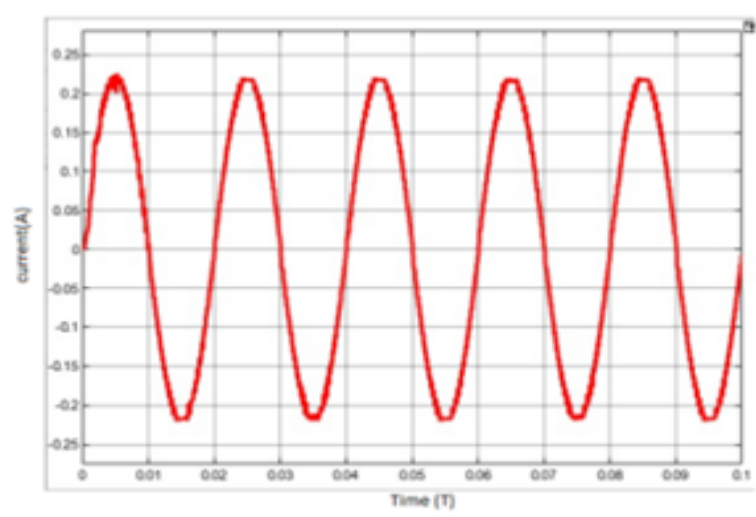

(a) PSO

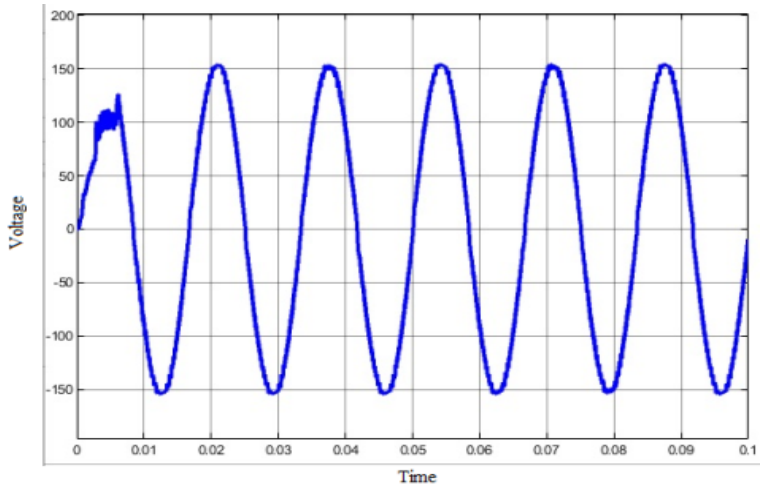

(b) $\mathrm{P} \& \mathrm{O}$ 


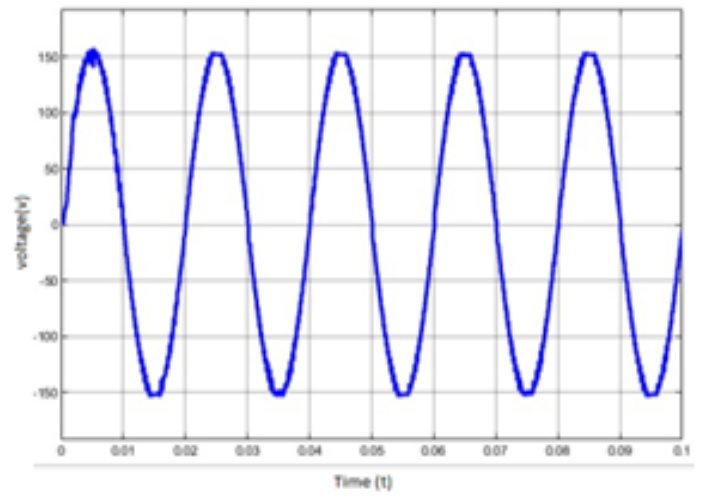

(b) PSO

Figure14. Micro-inverter (a) output current by $\mathrm{P} \& \mathrm{O}$ vs PSO (b) output voltage by P\&O vs PSO

The root mean square (RMS) of the output current and voltage are (0.7-0.8) Arms and (100-110) Vrms respectively as shown in figure 15 .
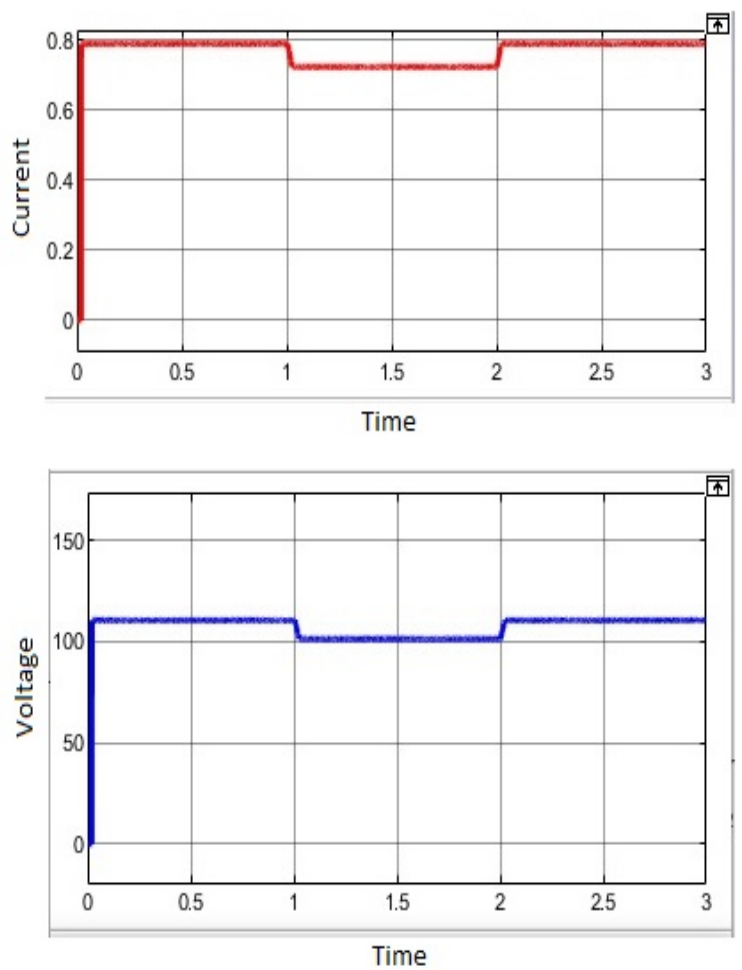

Figure.15 The root mean square current and voltage of the micro-inverter

The efficiency of the system when using the $\mathrm{P} \& \mathrm{O}$ algorithm is equal to $95.7 \%$, while that when using the PSO algorithm is equal to $96.8 \%$. The THD ratios of the output voltage and current using the $\mathrm{P} \& \mathrm{O}$ algorithm are $2.58 \%$ and $2.76 \%$ respectively, while that when using the $\mathrm{PSO}$ algorithm are $2.45 \%$ and $2.58 \%$. THD is compatible with the standard materials of the IEEE-SA Standards Board[18], as shown in Figure 16.

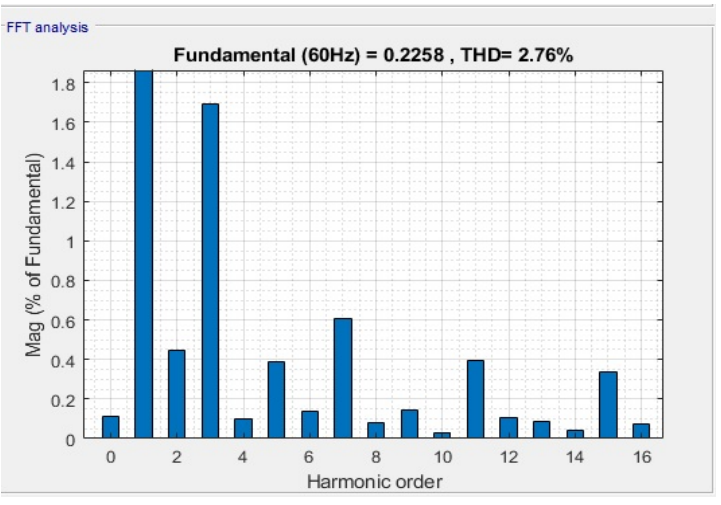

(a) $\mathrm{P} \& \mathrm{O}$

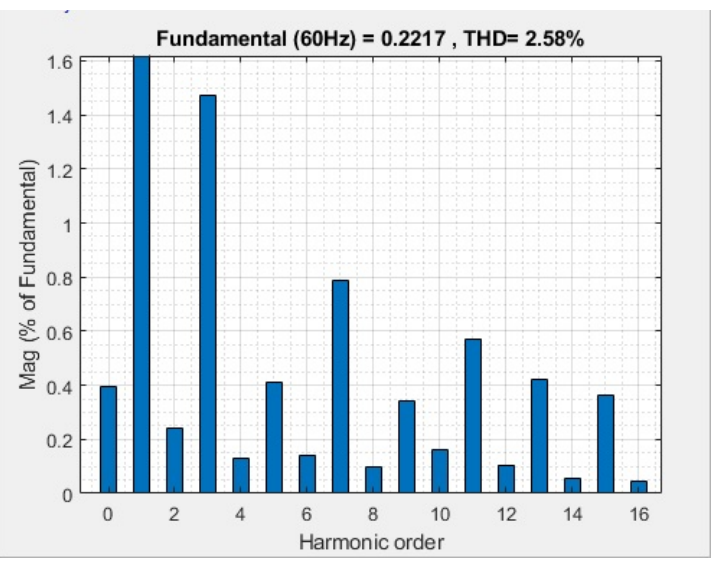

(a)PSO

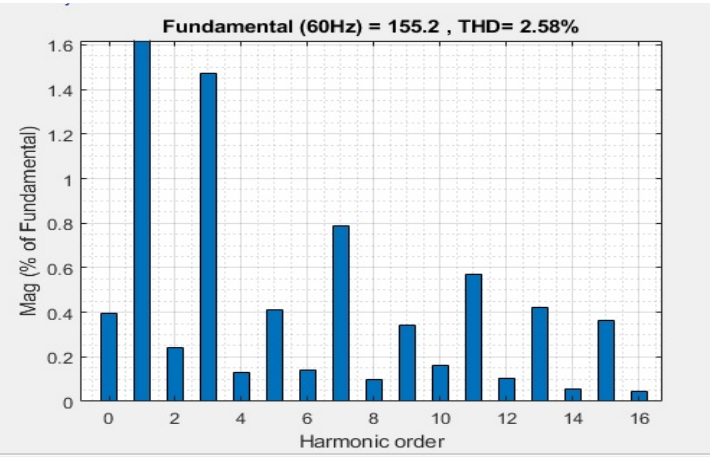

(b) $\mathrm{P} \& \mathrm{O}$

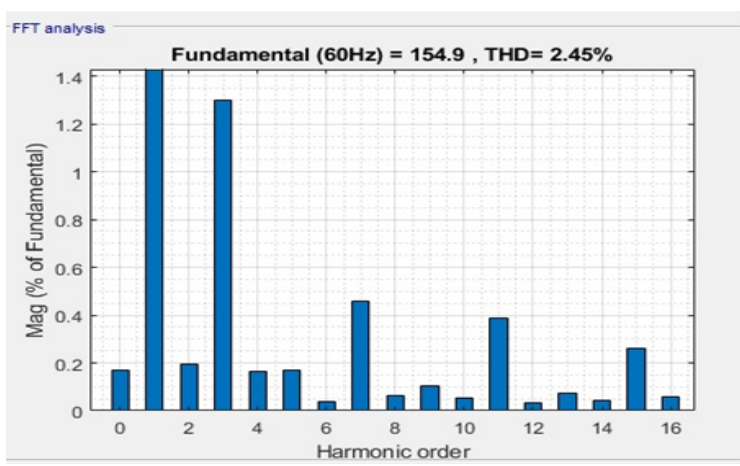

(b)PSO

Figure16. THD ratios (a) output current using $\mathrm{P} \& \mathrm{O}$ vs $\mathrm{PSO}$ (b) output voltage using $\mathrm{P} \& \mathrm{O}$ vs $\mathrm{PSO}$ 


\section{5- Discussion}

Several studies about the micro-inverter, including the study in[4] that based on the multi-output DC-DC converters design. The study uses monitoring for the maximum power point using the firefly algorithm. Microinverter is designed with cascaded H-bridge multilevel inverter (CHBMI) with isolated multiple-output zeta converter is used. The maximum input voltage for the PV is 50.2 VDC whereas the AC output voltage is $220 \mathrm{Vrms}$. The output voltage and current of the THD ratios are $2.9 \%$ and $2.5 \%$ respectively for the firefly algorithm. The PV system efficiency achieved by using P\&O 94.7\%. The present research focuses on the micro-inverter that consists of a boost converter, a comparison performance between Perturbation and observation (P\&O), and Particle Swarm Optimization (PSO) for harvesting the MPPT algorithm, and a full-bridge model controlled by 4 IGBT. The switching signals of the IGB were realized in an open-loop using the SPWM technique. The power is transferred from the inverter to the load using the LCL filter. The input maximum voltage from the $\mathrm{PV}$ is $80 \mathrm{~V}$ DC while the $\mathrm{AC}$ output voltage is 110 Vrms. The THD ratios output voltage and current are $2.58 \%$ and $2.76 \%$ respectively when the $\mathrm{P} \& \mathrm{O}$ algorithm is used, while that when using the PSO algorithm are $2.45 \%$ and 2.58 . The PV system efficiency achieved by using P\&O, PSO are $95.7 \%, 96.8 \%$.

\section{6- Conclusion}

This article presents the design of a Micro-inverter to convert the dc power generated by the photovoltaic panel to an ac power with the best performance. The designed circuit is implemented using the MATLAB / Simulink program. The Micro-inverter was designed with two-stage: the first is a Boost-converter; the second is the Full-Bridge Inverter. The performance of the $\mathrm{P} \& \mathrm{O}$ and the PSO algorithms was studied in case the shade falling on the PV panels. Each PV panel uses a micro-inverter that provides of MPPT algorithm to get the maximum power from the PV panel. The output results show that between the P\&O system and the PSO system have been compared to display the improvements. The results prove that the PSO algorithm is characterized by its speed and convergence in finding the MPP compared to the P\&O algorithm. we get a sine wave shape using the $\mathrm{H}$ - Bridge Inverter and a pure sine wave with $110 \mathrm{Vrms}$ at $60 \mathrm{~Hz}$ by using the LCL filter. We find that the efficiency value of the P\&O algorithm was $95.7 \%$, while The PSO algorithm was $96.8 \%$. The THD ratios of the micro-inverter output voltage and current are for $\mathrm{P} \& \mathrm{O}$ at $2.58 \%$ and $2.76 \%$ while for the PSO at $2.45 \%$ and $2.58 \%$.

\section{References}

[1] S. Hesari, "Design and implementation of maximum solar power tracking system using photovoltaic panels," Int. J. Renew. Energy Res., vol. 6, no. 4, pp. 1221-1226, 2016.

[2] S. Jiang, D. Cao, Y. Li, and F. Z. Peng, "Grid-connected boost-half-bridge photovoltaic microinverter system using repetitive current control and maximum power point tracking," IEEE Trans. power Electron., vol. 27, no. 11, pp. 4711-4722, 2012.
[3] C. K. Manikanta, I. M. Kumar, D. S. Reddy, G. L. Narayana, and P. Dharani, "POWER QUALITY IMPROVEMENT IN GRID CONNECTED SOLAR SYSTEM," J. Crit. Rev., vol. 7, no. 6, pp. 904-908, 2020.

[4] N. Mukundan and P. Jayaprakash, "Realization of Cascaded H-Bridge Multilevel Inverter Based Grid Integrated Solar Energy System With Band Stop Generalized Integral Control," IEEE Trans. Ind. Appl., vol. 57, no. 1, pp. 764-773, 2020.

[5] P. Sanjeevikumar, C. Dhanamjayulu, and B. Khan, "Artificial Neural Network and Newton Raphson (ANNNR) algorithm based Selective Harmonic Elimination in Cascaded Multilevel Inverter for PV Applications," IEEE Access, 2021.

[6] C. Hemalatha, M. V. Rajkumar, and G. V. Krishnan, "Simulation and Analysis of MPPT Control with Modified Firefly Algorithm for Photovoltaic System," Int. J. Innov. Stud. Sci. Eng. Technol., vol. 4863, no. November, pp. 2-6, 2016.

[7] M. Yaqoob Javed, A. Feroz Mirza, A. Hasan, S. Tahir Hussain Rizvi, Q. Ling, M. Majid Gulzar, M. Umair Safder and M. Mansoor, "A comprehensive review on a PV based system to harvest maximum power," Electronics, vol. 8, no. 12, p. 1480, 2019.

[8] D. P. Quesada, "DESIGN AND CONSTRUCTION OF AN ISOLATED DC-DC FLYBACK CONVERTER FOR SOLAR MPPT PURPOSES By," Sr. Thesis Electr. Eng. Illinois Urbana-Champaign, no. May, 2018.

[9] A. Belkaid, I. Colak, and K. Kayisli, "Implementation of a modified P\&O-MPPT algorithm adapted for varying solar radiation conditions," Electr. Eng., vol. 99, no. 3, pp. 839-846, 2017.

[10] A. I. Nusaif and A. L. Mahmood, "MPPT Algorithms (PSO, FA, and MFA) for PV System Under Partial Shading Condition, Case Study: BTS in Algazalia, Baghdad," Int. J. Smart Grid-ijSmartGrid, vol. 4, no. 3, pp. 100-110, 2020.

[11] R.-M. Chao, A. Nasirudin, I.-K. Wang, and P.-L. Chen, "Multicore PSO operation for maximum power point tracking of a distributed photovoltaic system under partially shading condition," Int. J. Photoenergy, vol. 2016, 2016.

[12] A. M. Eltamaly, M. S. Al-Saud, and A. G. Abo-Khalil, "Performance improvement of PV systems' maximum power point tracker based on a scanning PSO particle strategy," Sustainability, vol. 12, no. 3, p. 1185, 2020.

[13] M. F. Adnan, M. A. M. Oninda, M. M. Nishat, and N. Islam, "Design and simulation of a dc-dc boost converter with pid controller for enhanced performance," Int. J. Eng. Res. Technol., vol. 6, no. 09, pp. 27-32, 2017.

[14] T. Ajith Bosco Raj, R. Ramesh, J. R. Maglin, M. Vaigundamoorthi, I. William Christopher, C. Gopinath, and C. Yaashuwanth, "Grid connected solar PV system with SEPIC converter compared with parallel boost converter based MPPT," Int. J. Photoenergy, vol. 2014, 2014.

[15] I. Colak and E. Kabalci, "Developing a novel sinusoidal pulse width modulation (SPWM) technique to eliminate side band harmonics," Int. J. Electr. Power Energy Syst., 
vol. 44, no. 1, pp. 861-871, 2013.

[16] Y. Tang, P. C. Loh, P. Wang, F. H. Choo, F. Gao, and F. Blaabjerg, "Generalized design of high performance shunt active power filter with output LCL filter," IEEE Trans. Ind. Electron., vol. 59, no. 3, pp. 1443-1452, 2011.

[17] Yang Han, Mengling Yang, Hong Li, Ping Yang, Lin $\mathrm{Xu}$, Ernane Antônio Alves Coelho, and Josep M. Guerrero, "Modeling and stability analysis of \$ LCL \$type grid-connected inverters: A comprehensive overview," IEEE Access, vol. 7, pp. 114975-115001, 2019.

[18] C. K. Duffey and R. P. Stratford, "Update of harmonic standard IEEE-519: IEEE recommended practices and requirements for harmonic control in electric power systems," IEEE Trans. Ind. Appl., vol. 25, no. 6, pp. 1025-1034, 1989. 